\title{
Change of Glomerular Hemodynamics in Patients with Advanced Chronic Kidney Disease after Cilnidipine Therapy
}

\author{
Atsushi Satomura, Takayuki Fujita*, Yoshinobu Fuke, Yuki Wada and Koichi Matsumoto
}

Department of Nephrology, Hypertension and Endocrinology, Nihon University School of Medicine, Tokyo, Japan

\begin{abstract}
Cilnidipine, a dual calcium channel antagonist, is assumed to regulate hypertension via N- and L-type calcium channel. The $\mathrm{N}$-type calcium channel is associated with sympathetic nerve activation. This effect may improve the glomerular hemodynamics in the injured nephron, and may mitigate the progression of renal injury. To clarify the effect of cilnidipine in instances of already existing decreased renal blood flow, we examined the alteration of renal hemodynamics before and after cilnidipine therapy in patients with advanced chronic kidney disease (CKD). Cilnidipine was administrated daily to $17 \mathrm{CKD}$ patients with hypertension for 12 months. Another 16 patients were similarly administered amlodipine during this study, a long-acting L-type calcium channel antagonist has also been shown to be renoprotective. Glomerular filtration rate (GFR), effective renal plasma flow (ERPF), and protein excretion in 24-hour accumulated urine were measured at the start and end of the study. The parameters of renal hemodynamics were calculated by Gomez's estimation equation. Systolic blood pressure decreased to $80 \%$ of the level at the beginning of the study, and ERPF increased to $127 \%$ of the level at baseline. Glomerular capillary pressure on single nephron was reduced to $90 \%$, although total GFR decreased within the non-statistical change. Especially, renal vascular resistance ratio (RA/RE) on single nephron improved to $120 \%$. Cilnidipine improves ERPF and glomerular hypertension without worsening total renal function. $\mathrm{N}$ - and L-type calcium channel antagonist is effective and safe for patients with advanced CKD as a result of improvement of glomerular capillary resistance.
\end{abstract}

Keywords: N- and L-type calcium channel antagonist, glomerular hemodynamics, renal vascular resistance, glomerular capillary pressure, chronic kidney disease.

\section{INTRODUCTION}

Renal blood flow and glomerular filtration rate (GFR) decrease along with the progression of renal dysfunction in patients with chronic kidney disease (CKD) $[1,2]$. Continuous glomerular injury causes a decrease in normal nephron count in the bilateral kidney, and compensative increase of GFR in the residual individual nephron [3]. This phenomenon, called hyperfiltration, is one factor contributing to the progress of glomerular sclerosis. Hypertension, a complication in most CKD patients, also accelerates the progression rate of glomerular sclerosis [4]. Angiotensin converting enzyme inhibitor and angiotensin II receptor 1 blocker are known as renoprotective, anti-hypertensive drugs $[5,6]$. However, its single use is not enough for the renoprotective level of blood pressure in the most cases. Ca channel antagonists, especially dihydropyridine derivatives, are commonly used for the treatment of hypertension due to their property to maintain organ blood circulation $[7,8]$. However, the increase of renal blood flow brings hyperfiltration, and this ultimately accelerates glomerular sclerosis [9]. Recently, the long-acting dihydropyridine-type $\mathrm{Ca}$ channel antagonist is reported to play a role in the prevention of renal injury in addition to decreasing blood pressure [10]. Ca channels are classified as L-type, N-type, T-type, and P/Q-type by structure and distribution [11]. These subtypes are known to

*Address correspondence to this author at the Nihon University School of Medicine, 30-1 Oyaguchi-kamimachi, Itabashiku, Tokyo, 173-8610, Japan; Tel: +81-3-3972-8111 ext. 2414; Fax: +81-3-3972-1098;

E-mail: tfujita@med.nihon-u.ac.jp present in the kidney and serve to modulate the renal vascular tone. L-type $\mathrm{Ca}$ channel is substantially distributed within the vascular bed. It is established that the inhibition of Ltype $\mathrm{Ca}$ channel cause predominant dilatation of the afferent arteriole. T-type channel is reported to mediate the aldosterone secretion [12]. P/Q-type channel contributes the KClinduced constriction of the afferent arteriole [13]. Stimulation of the sympathetic nerve via the $\mathrm{N}$-type $\mathrm{Ca}$ channels causes norepinephrine excretion and increased heart rate, and contraction of the heart and vascular smooth muscle [14]. Thus, $\mathrm{N}$-type $\mathrm{Ca}$ channel antagonists may regulate the excitation of the renal sympathetic nerve, decrease renal vascular resistance [15]. Moreover, L- and N-type Ca channel antagonists are expected to play a role in the improvement of renal hemodynamics in patients with already advanced CKD. To clarify this hypothesis, we administrated cilnidipine, an L- and N-type Ca channel antagonist, to advanced CKD patients with hypertension, and examined the effect to hemodynamics.

\section{PATIENTS AND METHODS}

\section{Subjects}

Subjects included in the study were non-diabetic patients with chronic renal failure visiting to our hospital. All patients were clinically diagnosed as chronic renal failure due to chronic glomerulonephritis. Informed consent of 33 patients was obtained for participation in the study. 17 were assigned to the cilnidipine group, and the other 16 were assigned to the amlodipine group, mutually. Cilnidipine and amlodipine were continuously administered for 12 months during the 
Table 1. Background of Advanced CKD Patients with Cilnidipine or Amlodipine Therapy

\begin{tabular}{|c|c|c|c|}
\hline & & Cilnidipine Group & Amlodipine Group \\
\hline $\mathbf{n}$ & & 17 & 16 \\
\hline Age & (уо) & $66 \pm 6$ & $60 \pm 17$ \\
\hline Sex & $(\mathrm{M} / \mathrm{F})$ & $9 / 8$ & $7 / 9$ \\
\hline Heart rate (HR) & $(/ \mathrm{min})$ & $85 \pm 14$ & $86 \pm 12$ \\
\hline Systolic blood pressure (SBP) & $(\mathrm{mmHg})$ & $165 \pm 12$ & $155 \pm 7$ \\
\hline Diastolic blood pressure (DBP) & $(\mathrm{mmHg})$ & $93 \pm 10$ & $88 \pm 9$ \\
\hline Total protein $(\mathrm{TP})$ & $(\mathrm{g} / \mathrm{dL})$ & $7.1 \pm 0.8$ & $6.9 \pm 0.9$ \\
\hline Hemoglobin $(\mathrm{Hb})$ & $(\mathrm{g} / \mathrm{dL})$ & $11.6 \pm 1.5$ & $10.6 \pm 1.9$ \\
\hline 24-hour urinary protein (24UP) & (g/day) & $1.7 \pm 2.5$ & $1.5 \pm 2.2$ \\
\hline 24-hour creatinine clearance (GFR) & $(\mathrm{mL} / \mathrm{min})$ & $27 \pm 11$ & $31 \pm 17$ \\
\hline 24-hour urine volume (24UV) & (L/day) & $1.8 \pm 0.4$ & $1.8 \pm 0.6$ \\
\hline Effective renal plasma flow (ERPF) & $(\mathrm{mL} / \mathrm{min})$ & $105 \pm 35$ & $140 \pm 54$ \\
\hline
\end{tabular}

Values express mean \pm SD, There are no significant differences in each parameters.

study. The background of cilnidipine group and amlodipine group were as following, respectively: mean age $66 \pm 6$ years and $60 \pm 17$ years; sex (male / female) 9:8 and 7:9; systolic blood pressure (SBP) express $165 \pm 12 \mathrm{mmHg}$ and $155 \pm 7$ $\mathrm{mmHg}$, respectively; diastolic blood pressure (DBP) express $93 \pm 10 \mathrm{mmHg}$ and $88 \pm 9 \mathrm{mmHg}$, respectively; heart rate (HR) express $85 \pm 14 / \mathrm{min}$ and $86 \pm 12 / \mathrm{min}$, respectively; glomerular filtration rate (GFR) express $27 \pm 11 \mathrm{~mL} / \mathrm{min}$ and $31 \pm 17 \mathrm{~mL} / \mathrm{min}$, respectively; 24-hour accumulated urine protein excretion (24UP) express $1.7 \pm 2.5 \mathrm{~g} /$ day and $1.5 \pm 2.2 \mathrm{~g} /$ day, respectively. There were no significant differences between either group (Table 1).

\section{Study Protocol}

Patients were confirmed on several occasions as having systolic blood pressure above $150 \mathrm{mmHg}$, or diastolic blood pressure remaining over $90 \mathrm{mmHg}$, and then given a 12month treatment regimen of $10 \mathrm{mg} /$ day of cilnidipine or $5 \mathrm{mg} /$ day of amlodipine mutually according to the entry. Blood pressure was measured three times on every hospital visit by the digital oscillometric blood pressure monitor (Omuron HEM-907, Mie), and expressed as M \pm SD. GFR was estimated by 24 -hour creatinine clearance (24CCr), and effective renal plasma flow (ERPF) was calculated by Tc99m-mercaptoacetyltriglycine (MAG3) scintigram [16] at the start and end of the study. 24UP and 24-hour accumulated urine volume (24UV) were measured simultaneously. Parameters of renal hemodynamics were calculated by Gomez's estimation equation [17]. We assumed here that KF stayed within normal and stable ranges. There were few errors in KF due to comparison between the same patients or between subjects with similarly decreased renal function within a short period. Student's t-test was used for statistical analysis between pre- and post-treatment or between two therapy groups. The study was approved by the institutional ethical committee. Authors drew attention to the Code of Ethics of the World Medical Association (Declaration of Helsinki, 1964).

\section{Estimation of Glomerular Hemodynamics}

Parameters of renal hemodynamics were calculated by Gomez's estimation equation as the following:

$$
\begin{array}{ll}
\mathrm{FF} & =\mathrm{GFR} / \mathrm{ERPF} \\
\mathrm{CM} & =(\mathrm{TP} / \mathrm{FF}) \times \log _{\mathrm{e}}\{1 /(1-\mathrm{FF})\} \\
\Pi \mathrm{GC} & =5 \times(\mathrm{CM}-2) \\
\mathrm{PGC} & =\Pi \mathrm{GC}+\mathrm{PT}+\Delta \mathrm{PF} \\
\Delta \mathrm{PF} & =\mathrm{GFR} / \mathrm{KF} \\
\mathrm{RBF} & =\mathrm{RPF} \times\{1 /(1-\mathrm{Hct})\} \\
\mathrm{RA} & =1.328 \times(\mathrm{MBP}-\mathrm{PGC}) / \mathrm{RBF} \\
\mathrm{RE} & =1.328 \times \mathrm{GFR} / \mathrm{KF} \times(\mathrm{RBF}-\mathrm{GFR})
\end{array}
$$

\section{Abbreviations here are Used to Express}

$\mathrm{FF}=$ filtration fraction

$\mathrm{CM}=$ intraglomerular capillary protein concentration

$\mathrm{TP}=$ plasma total protein concentration

$\Pi \mathrm{GC}=$ intraglomerular capillary osmotic pressure

PGC = intraglomerular capillary blood pressure

PT = capillary hydraulic pressure $(10 \mathrm{mmHg})$

$\Delta \mathrm{PF} \quad=$ effective filtration pressure

$\mathrm{KF}=$ ultrafiltration coefficient $(0.812$ $(\mathrm{mL} / \mathrm{sec}) / \mathrm{mmHg})$

$\mathrm{RBF}=$ renal blood flow, Hct: hematocrit

$\mathrm{RA}=$ afferent arteriole resistance

$\mathrm{RE}=$ efferent arteriole resistance

$\mathrm{MBP}=$ mean blood pressure

We assumed here that KF stayed within normal and stable ranges. There were few errors in KF due to comparison 
between the same patients or between subjects with similarly decreased renal function within a short period.

\section{RESULTS}

\section{Alterations in Clinical Data and Total Renal Function After Medication}

HR significantly decreased in the cilnidipine group, on average from $85 \pm 14 / \mathrm{min}$ to $79 \pm 15 / \mathrm{min}$. SBP also significantly decreased from $165 \pm 12 \mathrm{mmHg}$ to $132 \pm 17 \mathrm{mmHg}$, and DBP decreased significantly from $93 \pm 10 \mathrm{mmHg}$ to 84 $\pm 10 \mathrm{mmHg}$. GFR express significant decrease from $27 \pm 11$ $\mathrm{mL} / \mathrm{min}$ to $22 \pm 10 \mathrm{~mL} / \mathrm{min}$. However, the other parameters changed within non-significant range. For example, ERPF increased from $105 \pm 35 \mathrm{~mL} / \mathrm{min}$ to $124 \pm 34 \mathrm{~mL} / \mathrm{min}$, and 24UP decreased from $1.7 \pm 2.5 \mathrm{~g} /$ day to $1.0 \pm 1.1 \mathrm{~g} /$ day. It is a point to take attention that the non-increase of GFR in spite of ERPF increasing. This indicates that cilnidipine could improve glomerular hyperfiltration. Following the same group average comparison expressed as percentage of pretreatment measurement in the amlodipine group, statistical significance was recognized only in SBP decreasing from $155 \pm 7 \mathrm{mmHg}$ to $136 \pm 8 \mathrm{mmHg}$. The other parameters stayed within non-significant range. 24UP non-significantly increased from $1.5 \pm 2.2 \mathrm{~g} /$ day to $2.1 \pm 3.3 \mathrm{~g} /$ day, and GFR and ERPF stayed in the previous level. The percentage of pretreatment measurement of 24UP decreased in cilnidipine group, but increased in the amlodipine group (Table 2 ).

Comparison of Alteration Rate in Clinical Data and Renal Function Between Cilnidipine and Amlodipine Therapy

Alteration rate in HR, SBP, GFR, ERPF, and 24UP was measured over 12 months, and was compared between cilnidipine and amlodipine groups. HR was reduced $7.4 \pm 8.1 \%$ by cilnidipine, and $5.8 \pm 10.5 \%$ by amlodipine. SBP showed a $20.0 \pm 7.6 \%$ reduction with cilnidipine, and $12.3 \pm 5.2 \%$ with amlodipine. GFR levels decreased by $19.6 \pm 13.6 \%$ with cilnidipine and showed a $6.3 \pm 16.6 \%$ increase by amlodipine. ERPF increased $27.0 \pm 51.7 \%$ with cilnidipine and $0.8 \pm 30.0 \%$ for amlodipine. 24UP decreased $6.4 \pm 53.3 \%$ in the cilnidipine group while increasing $92.0 \pm 192.1 \%$ in the amlodipine group. A similar level of desirable efficacy was recognized in the tested two calcium channel antagonists. Cilnidipine rather expressed a stronger drug effect on ERPF and 24UP (ERPF: $127 \%$ vs. $101 \%$, 24UP: $94 \%$ vs. $192 \%$ ) (Fig. 1).

\section{Alterations in Glomerular Hemodynamics After Medica- tion}

Glomerular hemodynamic parameters in a single nephron were calculated by Gomez's estimation equation. The obtained data were compared between prior to administration and after 12 months' cilnidipine treatment, and alteration rate of the above markers with cilnidipine treatment was compared to amlodipine. For cilnidipine, GFR decreased from $26.2 \mathrm{~mL} / \mathrm{min}$ to $21.5 \mathrm{~mL} / \mathrm{min}$; ERPF increased from 104.9 $\mathrm{mL} / \mathrm{min}$ to $123.7 \mathrm{~mL} / \mathrm{min}$, and FF decreased from 0.25 to 0.18 . ПGC decreased from $46.1 \mathrm{mmHg}$ to $41.5 \mathrm{mmHg}$, in other words, the improvement of hyperfiltration. RA/RE also improved from 12.9 to 15.5 . With amlodipine, on the other hand, GFR showed slight reduction from $31.4 \mathrm{~mL} / \mathrm{min}$ to $31.3 \mathrm{~mL} / \mathrm{min}$, ERPF changed from $140.2 \mathrm{~mL} / \mathrm{min}$ to 141.1 $\mathrm{mL} / \mathrm{min}$, FF from 0.22 to 0.21 , ПGC from $45.1 \mathrm{mmHg}$ to $43.9 \mathrm{mmHg}$, and RA/RE from 10.5 to 10.8 . There were no remarkable changes by amlodipine treatment in all parameters. These findings indicated that cilnidipine improved glomerular capillary hypertension and glomerular afferent/efferent arteriole resistance ratio more notably than amlodipine (Table 3).

\section{DISCUSSION}

The authors propose that L-type and N-type calcium channel antagonist cilnidipine may improve glomerular

Table 2. Change of Clinical Parameters in Advanced CKD Patients with Cilnidipine or Amlodipine Therapy

\begin{tabular}{|c|c|c|c|c|c|}
\hline & & \multicolumn{2}{|c|}{ Cilnidipine Group } & \multicolumn{2}{|c|}{ Amlodipine Group } \\
\hline & & Before & After & Before & After \\
\hline $\mathbf{n}$ & & 17 & 17 & 16 & 16 \\
\hline HR & $(/ \min )$ & $85 \pm 14$ & $79 \pm 15^{*}$ & $86 \pm 12$ & $80 \pm 7$ \\
\hline SBP & $(\mathrm{mmHg})$ & $165 \pm 12$ & $132 \pm 17 *$ & $155 \pm 7$ & $136 \pm 8^{*}$ \\
\hline DBP & $(\mathrm{mmHg})$ & $93 \pm 10$ & $84 \pm 10^{*}$ & $88 \pm 9$ & $81 \pm 11$ \\
\hline 24UP & (g/day) & $1.7 \pm 2.5$ & $1.0 \pm 1.1$ & $1.5 \pm 2.2$ & $2.1 \pm 3.3$ \\
\hline GFR & $(\mathrm{mL} / \mathrm{min})$ & $27 \pm 11$ & $22 \pm 10^{*}$ & $31 \pm 17$ & $31 \pm 22$ \\
\hline $24 \mathrm{UV}$ & (L/day) & $1.8 \pm 0.4$ & $1.8 \pm 0.5$ & $1.8 \pm 0.6$ & $1.7 \pm 0.6$ \\
\hline ERPF & $(\mathrm{mL} / \mathrm{min})$ & $105 \pm 35$ & $124 \pm 34$ & $140 \pm 54$ & $141 \pm 61$ \\
\hline $24 \mathrm{UNa}$ & (mEq/day) & $186 \pm 51$ & $172 \pm 54$ & $131 \pm 45$ & $131 \pm 45$ \\
\hline 24UK & (mEq/day) & $46 \pm 26$ & $32 \pm 21$ & $63 \pm 44$ & $66 \pm 30$ \\
\hline
\end{tabular}

Before: value prior to treatment, After: value after treatment, Values express mean \pm SD, HR: heart rate, SBP: systolic blood pressure, DBP: diastolic blood pressure, 24UP: 24-hour urine protein excretion, GFR: glomerular filtration rate estimated from 24-hour creatinine clearance, ERBF: effective renal blood flow estimated from MAG3 scintigram, 24UNa: 24hour urinary sodium excretion, 24UK: 24-hour urinary potassium excretion, *: statistically significant vs Before treatment. 


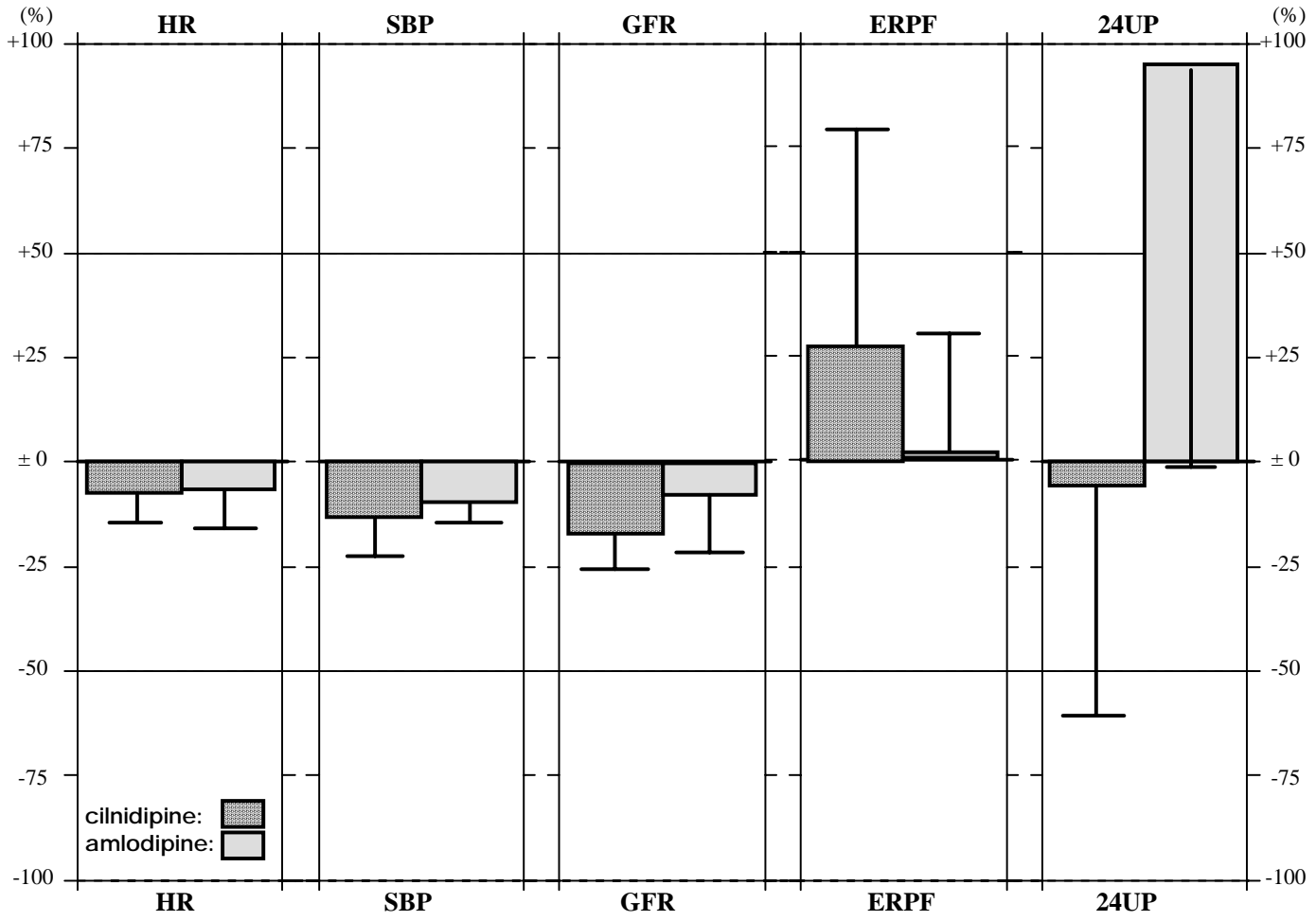

Fig. (1). Comparison of alteration rate in clinical data and renal function between cilnidipine and amlodipine therapy. Alteration rate in HR, SBP, GFR, ERPF, and 24UP was measured, and was compared in each group. A similar level of desirable efficacy was recognized in the tested two calcium channel antagonists. Cilnidipine rather expressed a stronger drug effect on ERPF and 24UP.

Table 3. Change of Renal Hemodynamics in Advanced CKD Patients with Cilnidipine or Amlodipine Therapy

\begin{tabular}{|c|c|c|c|c|c|}
\hline & & \multicolumn{2}{|c|}{ Cilnidipine Group } & \multicolumn{2}{|c|}{ Amlodipine Group } \\
\hline GFR & $(\mathrm{mL} / \mathrm{min})$ & $27 \pm 11$ & $22 \pm 10$ & $31 \pm 17$ & $31 \pm 22$ \\
\hline ERPF & $(\mathrm{mL} / \mathrm{min})$ & $105 \pm 35$ & $124 \pm 34$ & $140 \pm 54$ & $141 \pm 61$ \\
\hline $\mathrm{RBF}$ & $(\mathrm{mL} / \mathrm{min})$ & $162 \pm 58$ & $187 \pm 51$ & $211 \pm 98$ & $210 \pm 107$ \\
\hline $\mathrm{CM}$ & $(\mathrm{mmHg})$ & $8.13 \pm 0.81$ & $7.43 \pm 0.99$ & $7.72 \pm 0.89$ & $7.49 \pm 1.23$ \\
\hline PGC & $(\mathrm{mmHg})$ & $30.67 \pm 4.05$ & $27.13 \pm 4.94$ & $28.61 \pm 4.46$ & $27.47 \pm 6.15$ \\
\hline RA/RE & & $12.9 \pm 6.5$ & $15.5 \pm 9.8$ & $10.5 \pm 5.0$ & $10.8 \pm 6.4$ \\
\hline
\end{tabular}

Before: value prior to administration, After: value after treatment, Values express mean $\pm \mathrm{SD}$.

GFR: glomerular filtration rate, ERPF: effective renal plasma flow, FF: filtration fraction, RBF: renal blood flow, CM: intraglomerular capillary protein concentration, PGC: intraglomerular capillary osmotic pressure, ПGC: intraglomerular capillary blood pressure, RA: afferent arteriole resistance, RE: efferent arteriole resistance. 
hypertension and the decrease of renal blood flow. Furthermore, it is concluded that cilnidipine has a similar level of desirable efficacy as well as amlodipine, a known renoprotective L-type calcium channel blocker, in patients with advanced CKD. L-type calcium channel antagonists block the calcium channel of vascular smooth muscle cells and heart muscle cells, resulting in a decrease in systemic blood pressure. However, as shown in the first generation calcium channel antagonist, this induces reactive sympathetic nerve reflex and dilates the glomerular afferent arteriole, resulting in an increase of renal blood flow and glomerular filtration rate $[7,8]$. Because glomerular hypertension and glomerular hyperfiltration accelerate sclerosis over long periods of time, the safety of calcium channel antagonists in patients with advanced renal dysfunction has not been established [4,9].

Recently, long-acting L-type calcium channel blocker amlodipine was reported to have a renoprotective effect [10]. Amlodipine has been shown to increase renal blood flow without causing increase in GFR, and is expected to improve long-term prognosis. Cilnidipine has already demonstrated renoprotective effect in hypertensive animal models [18]. and similar effect was reported in human hypertensive nonCKD subjects $[19,20]$. In the present study, it is a unique aspect that most subjects were patients with advanced chronic renal failure due to chronic glomerulonephritis, and that hypertension is a secondary complication of primary renal disease. Renal blood flow and total glomerular filtration rate have already decreased at the start of antihypertensive drugs in spite of the increase in single nephron GFR [4,21].

We examined renal hemodynamics using Gomez's estimation equation, and suggested the benefit of calcium channel antagonists in respect to the improvement of glomerular hypertension. As Gomez's estimation equation being unsuitable for using in case of inconstant $\mathrm{Kf}$, the comparison was performed between the groups of similarly decreased renal function. In this investigation, we focused on the hemodynamic benefit of calcium channel antagonists in patients known to already have advanced chronic renal failure. Therefore, the background of subjects was stable in terms of renal dysfunction due to non-hypertensive mechanisms. In considering various clinical regulations Gomez's estimation equation may be a permissible assessment.

Study results revealed that L- and N-type calcium channel antagonist cilnidipine increased renal blood flow and effective renal plasma flow, and decreased glomerular filtration rate and capillary pressure. The resistances of glomerular afferent and efferent arterioles decrease, and the resistance ratio of both arterioles also improved. Moreover, the non-significant decrease of total GFR and the improvement of filtration fraction would suggest the improvement of elevated single nephron GFR. Amlodipine, a long-acting L-type calcium channel antagonist, also made no significant worsening of hemodynamic parameters in this study, and was recognized to be renoprotective. In comparing hemodynamic parameters of both groups, cilnidipine seems to be more desirable in rate of change. The cause of difference is considered to be via N-type calcium channel.

In conclusion, cilnidipine improves glomerular blood flow and glomerular hypertension without worsening total renal function. Dual calcium channel antagonist is effective and safe for patients with advanced CKD as a result of improvement of glomerular capillary resistance.

\section{REFERENCES}

[1] Cameron, J.S. The natural history of glomerulonephritis. In Progress in glomerulonephritis; Kincaid-Smith, P.; D'Aice, A.J.F.; Atkins, R.C., Eds.; Wiley: New York, 1979, pp. 1-25.

[2] Ofstad, J.; Horvei, G.; Kvam, F.I.; Morkrid, L.; Sekse, I.; Svarstad. E.; Iversen, BM. Glomerular hemodynamics in progressive renal disease. Kidney Int. Suppl., 1992, 36(5), S8-S14.

[3] Hostetter, T.H.; Olson, J.L.; Renke, H.G.; Venkatachalam, M.A.; Brenner, B.M. Hyperfiltration in remnant nephrons: a potentially adverse response to renal ablation. Am. J. Physiol., 1981, 24l(1), F85-F93.

[4] Locatelli, F.; Marcelli, D.; Comelli, M.; Alberti, D.; Graziani, G.; Buccianti, G.; Redaelli, B.; Giangrande, A. Northern Italian Cooperative Study Group. Proteinuria and blood pressure as causal components of progression to end-stage renal failure. Nephrol. Dial. Transplant., 1996, 11(3), 461-467.

[5] Ruggenenti, P.; Perna, A.; Gherardi, G.; Garini, G.; Zoccali, C.; Salvadori, M.; Scolari, F.; Schena, F.P.; Remuzzi, G. Renoprotective properties of ACE-inhibition in non-diabetic neohropathies with non-nephrotic proteinuria. Lancet, 1999, 354(9176), 359-364.

[6] Ishimitsu, T.; Kameda, T.; Akashiba, A.; Takahashi, T.; Ando, N.; Ohta, S.; Yoshii, M.; Inada, H.; Tsukada, K.; Minami, J.; Ono, H.; Matsuoka, H. Effects of valsartan on the progression of chronic renal insufficiency in patients with nondiabetic renal diseases. Hypertens. Res., 2005, 28(11), 865-870.

[7] Bertel, O.; Conen, L.D. Treatment of hypertensive emergencies with the calcium channel blocker nifedipine. Am. J. Med., 1985, 79(4A), 31-35.

[8] Hayashi, K.; Nagahama, T.; Oka, K.; Epstein, M.; Saruta, T. Disparate effects of calcium antagonists on renal microcirculation. $\mathrm{Hy}$ pertens. Res., 1996, 19(1), 31-36.

[9] Griffin, K.A.; Picken, M.M.; Bidani, A.K. Deleterious effects of calcium channel blockade on pressure transmission and glomerular injury in rat remnant kidneys. J. Clin. Invest., 1995, 96(2), 793-800.

[10] Dworkin, L.D.; Tolbert, E.; Recht, P.A.; Hersch, J.C.; Feiner, H.; Levin, R.I. Effects of amlodipine on glomerular filtration, growth, and injury in experimental hypertension. Hypertension, 1996, 27(2), 245-250.

[11] Hayashi, K.; Wakino, S.; Sugano, N.; Ozawa, Y.; Homma, K.; Saruta, T. $\mathrm{Ca}^{2+}$ channel subtypes and pharmacology in the kidney. Circ. Res., 2007, 100(2), 342-353.

[12] McCarthy, R.T.; Isales, C.; Rasmussen, H. T-type calcium channels in adrenal glomerulosa cells: GTP-dependent modulation by angiotensin II. Proc. Natl. Acad. Sci. USA, 1993, 90(8), 3260-3264.

[13] Adams, M.E.; Mintz, I.M.; Reily, M.D.; Thanabal, V.; Bean, B.P. Structure and properties of omega-agatoxin IVB, a new antagonist of P-type calcium channels. Mol. Pharmacol., 1993, 44(4), 681688.

[14] DiBona, G.F.; Kopp, U.C. Neural control of renal function. Physiol. Rev., 1997, 77(1), 75-197.

[15] Fujii, S.; Kameyama, K.; Hosono, M.; Hayashi, Y.; Kitamura, K. Effect of cilnidipine, a new dihydropiyridine $\mathrm{Ca}^{++}$-channel antagonist, on N-type $\mathrm{Ca}^{++}$channel in rat dorsal root ganglion neurons. $J$. Pharmacol. Exp. Ther., 1997, 280(3), 1184-1191.

[16] Bubeck, B.; Piepenburg, R.; Frethe, U.; Ehrig, B.; Hahn, K. A new principle to normalize plasma concentrations allowing singlesample clearance determinations in both children and adults. Eur. $J$. Nucl. Med., 1992, 19(7), 511-516.

[17] Gomez, D.M. Evaluation of renal resistances, with special reference to changes in essential hypertension. J. Clin. Invest., 1951, 30(10), 1143-1155.

[18] Konda, T.; Enomoto, A.; Matsushita, J.; Takahara, A.; Moriyama, $\mathrm{T}$. The N- and L-type calcium channel blocker cilnidipine suppresses renal injury in dahl rats fed a high-sucrose diet, an experimental model of metabolic syndrome. Nephron Physiol., 2005, 101(1), 1-13.

[19] Kojima, S.; Shida, M.; Yokoyama, H. Comparison between cilnidipine and amlodipine besilate with respect to proteinuria in hypertensive patients with renal diseases. Hypertens. Res., 2004, 27(6), 379-385. 
[20] Hoshide, S.; Kario, K.; Ishikawa, J.; Eguchi, K.; Shimada, K. Comparison of the effects of cilnidipine and amlodipine on ambulatory blood pressure. Hypertens. Res., 2005, 288(12), 1003-1008.

[21] Fujita, T.; Fuke, Y.; Satomura, A.; Hidaka, M.; Ohsawa, I.; Endo, M.; Komatsu, K.; Ohi, H. PGI2 analogue mitigates the progression rate of renal dysfunction improving renal blood flow without glomerular hypertension in patients with chronic renal insufficiency. Prostaglandins Leukot. Essent. Fatty Acids, 2001, 65(4), 223-227.

(C) Satomura et al.; Licensee Bentham Open.

This is an open access article licensed under the terms of the Creative Commons Attribution Non-Commercial License (http://creativecommons.org/licenses/by-nc/3.0/) which permits unrestricted, non-commercial use, distribution and reproduction in any medium, provided the work is properly cited. 